CHARLES E. M. DUNLOP

\title{
PERFORMATIVES AND DREAM SKEPTICISM
}

An important contention in Norman Malcolm's monograph, Dreaming, ${ }^{1}$ was that skepticism about one's present state (Am I awake or dreaming?) is untenable. Malcolm's book has been thoroughly and effectively criticized from a number of vantage points, but implicit in it is one argument against skepticism which these criticisms leave unscathed. I wish to call attention to this facet of Malcolm's doctrine, and to argue against it.

Malcolm devotes a great deal of space to analyzing the sentence 'I am awake', but his conclusions are not always consistent. At times (e.g., p. 118) he seems to think that the sentence can be used to make a true statement. At other points (120), however, he adopts the view that a person who says 'I am awake' is giving a performance (showing himself to be awake), rather than reporting or describing his own state. From this latter view an argument against the possibility of dream skepticism seems derivable. Since, in saying 'I am awake', a person is showing rather than claiming that something is the case, there is no room for the concept of error (120).

Now, Malcolm is certainly correct in pointing out the performative force of 'I am awake'. This can be seen by noting the occasions on which a grunt could be substituted without loss for 'I am awake' in answer to a question. But the skeptic should remain unmoved by this insight. For, it might be admitted that if I am really saying 'I am awake', then I am giving a performance, and cannot possibly be dreaming that $I$ am awake. Yet perhaps I am not really saying ' $I$ am awake'; perhaps I am only dreaming that I am saying it. To call attention to the performative force of 'I am awake' is not thereby to preclude the possibility of someone's dreaming that he gives the performance. Thus, the performative analysis of 'I am awake' is compatible with dream skepticism.

There is another anti-skeptical line which an advocate of the performative analysis could try at this point. If the sentence 'I am awake' had no 
descriptive content (Malcolm, p. 120), and could only be used performatively, then, like a cry of pain, it could not occur as the propositional object of the verb 'dream'. To take an example from an expression clearly lacking in descriptive content: I can dream that I said 'Ouch!', but I cannot dream that ouch. So the skeptical possibility - 'Perhaps at this moment I am dreaming that I am awake' - presumably could no longer be formulated. This result would reinforce Malcolm's suggestion (118) that the sentence 'I don't know whether I'm awake or dreaming' is nonsensical.

The conclusion here is much more surprising than in the case of at least many other performatives. The reason is that our intuitions usually keep us from thinking that sentences allocated exclusively for performative use could occur as objects of intentional verbs. There is nothing intuitively wrong with 'I am dreaming that I am awake', whereas (a) 'I am dreaming that I promise' sounds odd; we would, I think, tend to dismiss it in favor of (b) 'I am dreaming that I am promising'. (If we allowed (a) at all, we would have to construe 'I promise' non-performatively, describing a repetitive activity as in 'I pray' or 'I eat meat'.) And once modification (b) is accomplished, we are no longer left with a sentence whose use is exclusively performative, although in some circumstances 'I am promising' can substitute performatively for 'I promise'. In this way, our intiutions generally keep us from talking nonsense.

Suppose now, for the sake of argument, that the sentence 'I am awake' had no descriptive content whatever, being reserved exclusively for performative use. It would indeed follow that in one sense the skeptical possibility concerning dreams was unformulable, inasmuch as the sentence 'Perhaps at this moment $\mathbf{I}$.am dreaming that I am awake' would be unintelligible. But even if in this sense the skeptical possibility were unformulable, the skeptic could still employ his original argument. For example, if I presently suppose that the sentence ' $I$ am dreaming that I am awake' is senseless, I can still wonder whether my supposition is occurring in a dream, or in waking life. Opting for one alternative over the other introduces the possibility of error, which is precisely the foundation upon which the skeptic is forever building his case. If the skeptic is successful here, his argument can be generalized. The main point is just this: As long as a person can wonder whether any of his concerns are arising in a dream, or in waking life, there is always the possibility of his getting the answer wrong. Again, what more could skepticism require? 
There is still one item to be reckoned with. If it is assumed (falsely, I believe) that 'I am awake' is limited to performative use, then I am logically debarred from doubting that I am awake. Nevertheless, this turns out only to be a remark about the scope of the skeptic's vocabulary. For it is still possible for me to doubt that my presently occurring experience is part of my waking life. Thus, to say that the skeptical possibility is nonsense is only to say that one way of stating the skeptical problem has been eliminated. What is important is that other ways remain.

The argument against skepticism for which Malcolm is generally credited is based upon his well-known theory 'that if anyone holds that dreams are identical with, or composed of, thoughts, impressions, feelings, images, and so on (here one may supply whatever mental nouns one likes, except "dreams"), occurring in sleep, then his view is false' (52). Notice, however, that the 'argument from performatives' is logically independent of this highly controversial thesis. Any defense of dream skepticism, therefore, cannot rest content with an attack on Malcolm's denial of occurrent mental activity during sleep. I have attempted to supply the missing link and, if I am correct, it looks as if the skeptic's ground has not been cut away by Malcolm's appeal to the performative use of 'I am awake'. ${ }^{2}$

\section{University of Michigan-Flint}

NOTES

1 Routledge \& Kegan Paul, 1959, 1962. Page references will be inserted parenthetically into the text.

2 I thank Paul Peterson for his comments on an earlier version of this paper. 